\title{
Clinical Research on Tanreqing Injection Treatment of The Acute Lung Injury
}

\author{
Hua Zhang* \\ Department of Respiratory Medicine, The first Hospital of Hohhot City, Hohhot, Inner Mongolia 010000,China
}

\begin{abstract}
Objective: To discuss the clinical effect of Tanreqing injection in treatment of acute lung injury. Methods: 47 patients with acute lung injury in our hospital from January 2009 to February 2014 are selected and randomly divided into two groups. The control group has 24 cases and receives the conventional emergency treatment measures, including establishment of intravenous channel, loop support, oxygen inhalation, antibiotics application and primary trauma treatment, etc. There are 23 cases in experimental group, on the basis of treatment of the control group, they are treated with Tanreqing injection. The two groups are compared after treatment to study the clinical efficiency, blood gas index, SIRS score and the incidence of ARDS. Results: The treatment efficiency of patients with acute lung injury in experimental group is significantly higher than the control group ( $p$ $<0.05)$. After treatment, the blood gas index such as $\mathrm{PO}_{2}, \mathrm{PCO}_{2}, \mathrm{PO}_{2} / \mathrm{FiO}_{2}$ and others and SIRS score of patient with acute lung injury in both groups are obviously improved, and the experimental group is significantly better than the control group $(p<0.05)$. At the same time, the incidence of ARDS of patients with acute lung injury in the experimental group is significantly lower than the control group $(p<$ 0.05). Conclusion: The use of tanreqing injection during the treatment of acute lung injury can effectively improve patients' ventilation and alleviate symptoms of respiratory distress and has good prognosis.
\end{abstract}

\author{
KEYWORDS \\ Tanreqing injection \\ Acute lung injury \\ Curative effect
}

\section{Introduction}

Acute lung injury is one of the common severe clinical diseases. It refers to the syndrome after alveolar epithelium and vascular endothelial cells are injured by severe trauma, infection and others, the main manifestations are progressive hypoxemia and respiratory distress,

Copyright (C) 2016 Hua Zhang

doi: 10.18686/aem.v5i3.15

Received: August 9, 2016; Accepted: September 3, 2016; Published online: September 17, 2016

This is an open-access article distributed under the terms of the Creative Commons Attribution Unported License (http://creativecommons.org/ licenses/by-nc/4.0/), which permits unrestricted use, distribution, and reproduction in any medium, provided the original work is properly cited.

${ }^{\star}$ Corresponding author: Department of Respiratory Medicine, The first Hospital of Hohhot City, Hohhot, Inner Mongolia 010000, China. E-mail: lvwensi12345@sina.com acute lung injury's condition is usually complex, serious, rapid, often leads to acute respiratory distress syndrome and even multiple organ dysfunction syndrome, have high clinical mortality rate $[1,2]$. There is no effective treatment at present, the hospital usually adopts emergency treatment such as primary trauma or disease treatment, mechanical ventilation, hormone application, etc, clinical effect is not good. The author selected 47 patients with acute lung injury from January 2009 to February in 2014, on the basis of conventional emergency treatment measures, applied Tanreqing injection to dicuss the clinical effect of Tanreqing injection on the treatment of acute lung injury.

\section{Materials and methods}

\subsection{Clinical data}

The author selected 47 patients with acute lung injury in 
our hospital from January 2009 to February 2014, and these patients were all consistent with the acute lung injury diagnostic criteria of severe medical branch of Chinese Medical Association [3]. These selected acute lung injury patients were divided into two groups by random number: there were 24 cases in control group, 15 males and 9 females. They aged from 20 to 62 years old and the average age was $(43.2 \pm 6.7 \mathrm{~mm})$ years old, APACHE score was $18.6 \pm 5.4$. There were 23 cases in experimental group, of which 15 cases were male and 8 cases were female. They aged from 21 to 65 years old with average of $(44.0 \pm 7.5$ $\mathrm{mm}$ ) years old, APACHE score was $18.4 \pm 5.7$. The two groups of patients with acute lung injury had no significant difference in age, sex, APACHE score and other clinical data $(p>0.05)$.

\subsection{Method}

\subsubsection{Treatment}

The Control group received conventional emergency treatment measures, including establishment of intravenous channel, loop support, oxygen inhalation, antibiotics application and primary trauma treatment. On the basis of treatment of the control group, experimental group was administrated by intravenous drip of $20 \mathrm{~mL}$ of Tanreqing injection $+250 \mathrm{~mL}$ of $5 \%$ glucose injection, once a day, treated for 7 days.

\subsubsection{Research Methods}

The author screened patients with acute lung injury in our hospital from January 2009 to February 2014 and found 47 cases of acute lung injury patients conformed to the study. Random method was used to divide them into two groups. There were 24 cases in control group, accounting for 51\% of the total. Conventional emergency treatment measures were used, including establishment of intravenous channel, loop support, oxygen inhalation, antibiotics application and primary trauma treatment, etc. there were 23 cases in experimental group, accounting for $49 \%$ of the total. On the basis of treatment of the control group, they were treated with Tanreqing injection. The clinical effect of two groups was compared after treatment. The blood gas index, SIRS score and the incidence of ARDS were mainly compared.

\subsection{Observation indicators}

The blood gas indexes such as $\mathrm{PO}_{2}, \mathrm{PCO}_{2}, \mathrm{PO}_{2} / \mathrm{FiO}_{2}$ and others of patients with acute lung injury were determined and SIRS score was evaluated before and after treatment. At the same time, cases of acute lung injury patients with invasive mechanical ventilation and acute respiratory distress syndrome (ARDS) were recorded.

\subsection{Statistical processing}

Using SPSS 12.0 software to do statistical processing, measurement data were treated by $t$ test, count data were treated by chi-square test, There were statistical differences due to $p<0.05$.

\section{Results}

\subsection{Comparition of clinical effective rate between two groups}

In acute lung injury patients of the control group, 3 cases turned to invasive mechanical ventilation treatment, the clinical effective rate was $87.5 \%(21 / 24)$.

In acute lung injury patients of the experimental group, 1 case turned to invasive mechanical ventilation treatment, the clinical effective rate was $95.6 \%(22 / 23)$.

The clinical effective rate of the experimental group was significantly higher than the control group $(p<0.05)$. See Table 1 .

Table 1. Comparition of clinical effective rate between two groups.

\begin{tabular}{cccc}
\hline Group & Case & $\begin{array}{c}\text { Case of invasive } \\
\text { mechanical ventilation }\end{array}$ & Effective rate (\%) \\
\hline $\begin{array}{c}\text { control } \\
\text { group }\end{array}$ & 24 & 3 & 87.5 \\
$\begin{array}{c}\text { experimental } \\
\text { group }\end{array}$ & 23 & 1 & 95.6 * \\
\hline
\end{tabular}

${ }^{*}$ Compared with the control group, $p<0.05$.

\subsection{Comparison of blood gas indexes and SIRS score of two groups between before and after treatment}

Before treatment, the control group and experimental group had no statistical difference in blood gas indexes such as $\mathrm{PO}_{2}, \mathrm{PCO}_{2}, \mathrm{PO}_{2} / \mathrm{FiO}_{2}$ and others and SIRS score $(p$ $>0.05$ ). After treatment, the above indexes were obviously

Table 2. Comparison of blood gas indexes of two groups between before and after treatment.

\begin{tabular}{|c|c|c|c|c|}
\hline \multirow{2}{*}{ Laboratory index } & \multicolumn{2}{|c|}{ Control group } & \multicolumn{2}{|c|}{ Experimental group } \\
\hline & Before treatment & After treatment & Before treatment & After treatment \\
\hline $\mathrm{PO}_{2}(\mathrm{mmHg})$ & $78.1 \pm 6.5$ & $90.4 \pm 8.5$ * & $78.6 \pm 7.0$ & $105.9 \pm 10.3$ * \\
\hline $\mathrm{PCO}_{2}(\mathrm{mmHg})$ & $28.3 \pm 3.1$ & $34.2 \pm 3.4$ * & $28.7 \pm 2.8$ & $40.2 \pm 3.8$ * \\
\hline $\mathrm{PO}_{2} / \mathrm{FiO}_{2}(\mathrm{mmHg})$ & $221.6 \pm 20.3$ & $294.6 \pm 42.8$ * & $222.1 \pm 19.7$ & $354.8 \pm 50.2$ * \\
\hline SIRS score & $3.8 \pm 1.5$ & $2.3 \pm 0.9$ * & $3.9 \pm 1.3$ & $1.2 \pm 0.5^{*}$ \\
\hline
\end{tabular}

*compared with before treatment, $p<0.05$; compared with control group, $p<0.05$. 
improved in both groups and the experimental group was significantly better than the control group $(p<0.05)$. See Table 2.

\subsection{Comparison of the occurrence rate of ARDS between two groups}

The occurrence rate of ARDS in the control group was $41.2 \%$, while the experimental patient was $19.5 \%$. Thus, the occurrence rate of ARDS in experimental group was significantly lower than the control group $(p<0.05)$. See Table 3.

Table 3. Comparison of the occurrence rate of ARDS between two groups.

\begin{tabular}{cccc}
\hline Group & Case & ARD Case & $\begin{array}{c}\text { Occurrence rate } \\
(\%)\end{array}$ \\
\hline Control group & 24 & 10 & 41.6 \\
Experimental group & 23 & 5 & 21.7 * \\
\hline
\end{tabular}

${ }^{*}$ Compared with control group, $\mathrm{p}<0.05$.

\section{Discussion}

In recent years, with the continuous development and progress of our economy and traffic, the amount of trauma patients is showing an increasing trend year by year. Severe trauma has become to be one of main causes of acute lung injury. When severe trauma occurs, it gives huge impact force to chest wall, causing chest cavity to become narrow, intrathoracic pressure to rise suddenly, compression of lung parenchyma, leading to hemorrhage and edema. Then the external force disappear, intrathoracic pressure gets fast recovery, the generation of negative pressure causes lung parenchyma damage again, bleeding is aggravated. Existing research showed that [4] the pathogenesis of acute lung injury is excessive inflammatory response of the whole body. Severe trauma causes the release of IL-6, IL-8, TNF alpha and other inflammatory mediators, at the same time, it will activate the macrophage system, The inflammatory cytokines release further activate the neutrophils and others, resulting in accumulation of oxygen free radicals and arachidonic acid to form a cascade amplification effect, eventually leading to excessive systemic inflammatory response, the body's inflammatory steady-state becomes unbalanced, acute lung injury occurs.

The purpose of emergency treatment of acute lung injury is to prevent the progress of condition to acute respiratory distress syndrome. The key is to effectively control the body excessive inflammation in early stage. Tanreqing injection is a new kind of Chinese patent medicine. The main ingredients are skullcap, cornugorais and honeysuckle, etc. Modern pharmacology study proves that $[5,6]$ the flavonoids in skullcap has significant anti-inflammatory and anti-allergy effect. Meanwhile, the keratin of cornugorais contains a variety of active amino acid, which can effectively relax bronchial and has smooth wheezing expectorant effect. In addition, the chlorogenic acid and isochlorogenic acid composition in floslonicerae has the function of sedative antipyretic, immunity adjustment and anti-pathogenic microorganism. The Tanreqing injection applied in acute lung injury can effectively protect alveolar endothelial cells, promote restoration of the damaged cells, and improve the function of alveolar ventilation.

The study showed that the treatment efficiency of experimental group was significantly higher than the control group $(p<0.05)$. After treatment, the control group and experimental group's blood gas indexes such as $\mathrm{PO}_{2}$, $\mathrm{PCO}_{2}, \mathrm{PO}_{2} / \mathrm{FiO}_{2}$ and others and SIRS score were obviously improved, and the experimental group was significantly better than the control group $(p<0.05)$. At the same time, the occurrence rate of ARDS in the experimental group was also significantly lower than the control group $(p<$ 0.05).

Above all, Tanreqing injection for treatment of acute lung injury is clinically effective it can effectively improve the ventilation conditions, alleviate symptoms of respiratory distress and have clinical popularization using value.

\section{Reference:}

1. Liang ZH. Effect observation of Xuebijing injection in treatment of acute lung injury caused by trauma. Practical Journal of Cardiac Cerebral Pneumal and Vascular Disease. 2012;20(1):111-112.

2. Wu JH, Ya J. Diagnosis and treatment analysis of 178 cases of severe chest trauma. Practical Journal of Cardiac Cerebral Pneumal and Vascular Disease. 2011;19(3):462.

3. Intensive medical branch of Chinese medical association. Diagnosis and treatment guideline of acute lung injury/ acute respiratory distress syndrome (2006). Chinese Journal of Emergency Medicine. 2007;16(4):343-349.

4. Liu HB, Cui NQ, Li DH, et al. Role of Kupffer cells in acute hemorrhagic necrotizing pancreatitis-associated lung injury of rats. World J Gastroenterol. 2006;12(3):403407.

5. Yang SX, Zhao YL, Zeng YJ, et al. Curative effect observation of tanreqing injection in the treatment of traumatic acute lung injury. Guangxi Medical Journal. 2010;32(2):143-146.

6. Han YH. Clinical curative effect observation of Tanreqing injection in the treatment of COPD complicated with respiratory failure. Chinese pharmacy. 2007;18(27):2137. 